\title{
Is the CD4/CD8 Ratio an Effective Indicator for Clinical Estimation of Adoptive Immunotherapy for Cancer Treatment?
}

\author{
Goki Shindo $^{1}$, Takayoshi Endo ${ }^{1}$, Masamitsu Onda ${ }^{1}$, Shigenori Goto ${ }^{2}$, Yoju Miyamoto ${ }^{3}$, Toru Kaneko ${ }^{3}$ \\ ${ }^{1}$ Cardiothoracic Department, Meditopia Numazu Clinic, Numazu, Japan; ${ }^{2}$ Department of Immunotherapy, Seta Clinic Tokyo, Tokyo, \\ Japan; ${ }^{3}$ Department of Immunotherapy, Seta Clinic Shin-Yokohama, Yokohama, Japan. \\ Email: gshindo@meditopia.or.jp
}

Received September $12^{\text {th }}, 2013$; revised October $10^{\text {th }}, 2013$; accepted October $18^{\text {th }}, 2013$

Copyright (C) 2013 Goki Shindo et al. This is an open access article distributed under the Creative Commons Attribution License, which permits unrestricted use, distribution, and reproduction in any medium, provided the original work is properly cited.

\begin{abstract}
Background: The importance of immunotherapy in cancer treatment has been increased owing to its non-toxicity and application to personalized medicine. However, precise estimation indices of immunotherapy have yet to be established. To determine effective evaluation indices of immunotherapy for cancer treatment, we analyzed the CD4/CD8 ratio under various conditions in clinical patients with advanced cancer. Patients and Methods: Thirty-four patients who underwent one course of adoptive activated immunotherapy with or without additional conventional chemotherapy were enrolled. Before and after one course of immunotherapy, changes in the CD4/CD8 ratio were estimated by flow cytometry. Results: All patients showed a tendency toward a decrease in the CD4/CD8 ratio during a 3-month period after one course of adoptive activated T lymphocyte immunotherapy. Patients who had undergone prior surgery showed a remarkable increase in CD8 T cell number. Thus, adoptive activated T lymphocyte immunotherapy improves immunological ability against cancer invasion. The Eastern Cooperative Oncology Group's performance status during one course of immunotherapy was significantly improved in the antecedent surgery group, with no evidence of improved PS in the non-antecedent surgery group. Patients with an increased CD4/CD8 ratio $(n=6)$ may have a worse outcome during adoptive activated T lymphocyte immunotherapy even with an additional course of immunotherapy. Improved actuarial survival rate of patients in the antecedent surgery group showed significant long-term benefit compared to those in the non-antecedent surgery group $(\mathrm{p}=0.0298)$, as previously reported. Conclusion: The CD4/CD8 ratio is a significant indicator of outcome of adoptive activated T lymphocyte immunotherapy.
\end{abstract}

Keywords: Immunotherapy; Adoptive Activated T Lymphocyte therapy; Flow Cytometry; Performance Status; Advanced Cancer

\section{Introduction}

Immunotherapy plays an important role in cancer treatment because of its non-toxic therapeutic effect and because it can be highly personalized by using autologous activated lymphocytes obtained from patients. Recent technological progress in flow cytometry using laser beams directed onto a hydrodynamically focused stream of liquid has made it possible to count suspended cells and molecular particles on the cell surface at a rate of thousands of particles per second.

Since Rosenberg et al. first applied lymphokine-activated killer (LAK) cell immunotherapy with direct injection of interleukin 2 (IL-2) to patients for clinical use in 1986 [1], despite subsequently observed adverse effects of the original procedure, immunotherapy has been developed steadily over the past 20 years as a personalized non-toxic therapy for cancer patients.

Egawa established modified adoptive immunotherapy for clinical use in 1999 without direct injection of IL-2 into the human body [2]. Since then, supportive evidence of the clinical use of immunotherapy for various types of cancers has been reported [3-6]. However, the effective response rate according to the complete/partial response outlined in the RECIST criteria was determined to be low, adverse reactions were rarely observed, and patients generally showed a good Eastern Cooperative Oncology Group (ECOG) performance status (PS) during the course of immunotherapy. A recent phase 3 trial using Egawa's modified adoptive immunotherapy in combina- 
tion with chemotherapy also showed important significant additive effects of immunotherapy compared to chemotherapy alone in lung cancer patients at all clinical stages, as well as a positive effect on quality of life (QOL) until near the time of death in advanced lung cancer patients [7]. To date there have been few reports on the efficacy of immunotherapy using accurate estimation indices $[8,9]$, especially for modified adoptive immunotherapy. On the basis of recent advances in flow cytometry, we aimed to identify effective estimation indices for evaluating the efficacy of immunotherapy, either alone or combined with chemotherapy, in the course of cancer treatment. We chose the CD4/CD8 ratio as an indicator of immunological response before and after one course of adoptive immunotherapy treatment in patients with advanced clinical stages of disease.

\section{Patients and Methods}

\subsection{Patient Characteristics}

Thirty-four patients with advanced stage III or IV cancer who underwent one course of adoptive activated immunotherapy with measurement of their CD4/CD8 ratio before and after immunotherapy at Meditopia Numazu Clinic, Seta Clinic Tokyo, and Seta Clinic Shin-Yokohama between December 2008 and June 2012 were enrolled. Written informed consent was obtained from all patients before starting immunotherapy.

The primary sites of disease in the 34 patients are shown in Table 1(A). Fourteen (41.2\%) patients had cancer of the lung and $9(26.5 \%)$ had cancer of the ovary; cancers in the remaining patients included colorectal and stomach. Patient characteristics are summarized in Table 1(B). To clarify the effect of antecedent surgery which was reported previously to be one of the most important benefits for patients with advanced cancer [10], patients were divided into two groups - antecedent surgery and non-antecedent surgery groups - and the CD4/CD8 ratio was analyzed separately. All patients in the antecedent surgery group underwent curative surgery in accordance with the Japanese guidelines for surgical procedures for cancer in the organ affected and were found to have Un-

Table 1. Primary cancer sites and patient characteristics.

\begin{tabular}{|c|c|c|c|c|}
\hline \multicolumn{5}{|c|}{ (A) Primary cancer sites } \\
\hline Cancer site & Total $(\%)$ & Anteced & t surgery group & Non-antecedent surgery group \\
\hline lung & $14(41.2)$ & & 3 & 11 \\
\hline ovary & $9(26.5)$ & & 9 & 0 \\
\hline uterus & $2(5.9)$ & & 1 & 1 \\
\hline colorectal & $2(5.9)$ & & 2 & 0 \\
\hline melanoma & $2(5.9)$ & & 2 & 0 \\
\hline stomach & $1(3.0)$ & & 0 & 1 \\
\hline pancreas & $1(3.0)$ & & 0 & 1 \\
\hline kidney & $1(3.0)$ & & 1 & 0 \\
\hline throat & $1(3.0)$ & & 1 & 0 \\
\hline Multiple myeloma & $1(3.0)$ & & 0 & 1 \\
\hline total & $34(100)$ & & 19 & 15 \\
\hline \multicolumn{5}{|c|}{ (B) Patient characteristics in each group } \\
\hline & Total $(\mathrm{n}=34)$ & $\begin{array}{l}\text { Antecedent surgery group } \\
\qquad(\mathrm{n}=19)\end{array}$ & $\begin{array}{l}\text { Non-antecedent surgery } \\
\text { group }(n=15)\end{array}$ & $\begin{array}{l}\text { P value (surg. vs } \\
\text { non-surg.) }\end{array}$ \\
\hline age $(y / o)$ & $58.6(28-80) 60^{\prime}(41.2 \%)$ & $58.6(28-78)$ & $58.5(30-80)$ & N. S. \\
\hline gender $\mathrm{M}(\%) / \mathrm{F}(\%)$ & $12(35.3) / 22(64.7)$ & $2(10.5) / 17(89.5)$ & $10(66.7) / 5(33.3)$ & 0.0025 \\
\hline stage III (\%)/IV(\%) & $8(22.5) / 26(76.5)$ & $5(26.3) / 14(73.7)$ & $4(26.7) / 11(73.3)$ & N.S \\
\hline PS $0(\%) / 1(\%)$ & $24(70.6) / 10(29.4)$ & $14(73.7) / 5(26.3)$ & $10(66.7) / 5(33.3)$ & N. S. \\
\hline $\begin{array}{l}\text { time interval (mos) } \\
\text { OP(Rec)-IT }\end{array}$ & & 28.16 & 2.7 & 0.0002 \\
\hline combination IT $+\mathrm{CT}$ & $25 / 34(73.5 \%)$ & $12 / 19(63.2)$ & $13 / 15(86.7)$ & N. S. \\
\hline
\end{tabular}

IT: immunothrapy, CT: chemotherapy, OP-IT: surgery to IT, Rec-IT: recurrence of cancer to IT. 
ion for International Cancer Control TNM stage 3 or 4 disease.

The ECOG PS at the first, fourth, and sixth administration of $\alpha \beta \mathrm{T}$ cell infusion was estimated. When patients were stable and tolerated one course of immunotherapy, immunotherapy was continued periodically with a 2- to 4-week interval for as long as possible, according to patients' request and their condition.

There were no significant differences in age, ECOG PS before starting immunotherapy, or proportion of patients undergoing combination therapy involving chemotherapy between the two groups. By contrast, there were significant differences in gender (more female patients in the antecedent surgery group, especially in the case of ovarian cancer) and the time interval before initiation of one course of immunotherapy (16.0 vs. 2.7 months).

\subsection{Adoptive Activated T Lymphocyte Immunotherapy}

Adoptive activated $\mathrm{T}$ lymphocyte immunotherapy is a non-specific therapy without sensitization by cancerspecific peptides. During the culture period there is promoted killer activities and a decrease in the number of regulatory $\mathrm{T}$ lymphocytes which suppress tumor immunity. Peripheral blood lymphocytes and mononuclear cells are harvested by centrifugation and $>1 \times 10^{6}$ harvested cells are cultured with an immobilized anti-CD3 antibody and IL-2 for 14 days, obtaining $>5 \times 10^{9}$ lymphocytes on average. This method of therapy is termed $\alpha \beta \mathrm{T}$ immunotherapy. The cultured lymphocytes consist of $61 \% \pm 15 \% \mathrm{CD} 8 \mathrm{~T}$ cells and $30 \% \pm 15 \% \mathrm{CD} 4 \mathrm{~T}$ cells, an average $\mathrm{CD} 4 / \mathrm{CD} 8$ ratio of $0.8(0.66-2.9)$, and a small percentage of natural killer (NK) cells and NK T cells, indicating that CD8 $\mathrm{T}$ lymphocytes proliferate more at a greater rate than $\mathrm{CD} 4 \mathrm{~T}$ lymphocytes during the 2-week culture period $[11,12]$. The precise processing of these cells is described elsewhere [10-12]. Expanded CD8-rich $\mathrm{T}$ lymphocytes were infused intravenously once every 2 weeks up to 6 times for 3 months during one course of immunotherapy.

\subsection{Flow Cytometry}

Heparinized peripheral blood samples were collected for each patient before and after one course of immunotherapy and $\beta, \mathrm{CD}^{+}$and $\mathrm{CD}^{+} \mathrm{T}$ cell counts, and the CD4/ CD8 ratio were measured by flow cytometry $[13,14]$. Prior to this study, we determined the influence of storage temperature and time between peripheral blood collection and assay initiation on the results of flow cytometry, and we established that consistent results were obtained when peripheral blood was stored at $18^{\circ} \mathrm{C}$ $22^{\circ} \mathrm{C}$ for 1 day before phenotypic analysis. Phenotypic analysis of peripheral blood mononuclear cells was carried out by whole-blood staining with Optlyse $\mathrm{C}$ lysis solution. The absolute numbers of $\alpha \beta, \mathrm{CD} 4$ and CD8 T cells were determined using Flow-Count ${ }^{\mathrm{TM}}$ fluorosphere internal standard beads. These reagents and monoclonal antibodies against CD3, CD4, CD8 and TCR pan $\alpha \beta \mathrm{T}$ cells were purchased from Beckman Coulter (Brea, CA). Cytomics FC 500 and/or Gallios flow cytometer (Beckman Coulter) was used for data acquisition and the data were analyzed with CXP and/or Kaluza software (Beckman Coulter).

\subsection{Statistical Analysis}

The chi-squared test was used to compare patient demographic, clinical, and laboratory variables, with the MannWhitney $U$ test used for qualitative variables and the Mantel-Haenszel procedure used for analyzing multiple 2 $\times 2$ contingency tables. Fisher's Student $t$ test was used for quantitative variables in the case of equal variance of the two comparable populations, and Welch's $t$ test was used when the assumption of equality of the variances was dropped. Patient survival was analyzed using the Kaplan-Meier method. Differences in survival were determined using the log-rank test for univariate analysis. Statcel Ver. 2 for Windows Excel software was used for analysis.

\section{Results}

During one course of immunotherapy, six intravenous infusions of $\alpha \beta$ T cells ( $3-10 \times 10^{9}$ cells) were infused at intervals of approximately 2 weeks. Overall, $73 \%$ of all patients received additional conventional therapy when indicated, with an appropriate interval between immunotherapy and chemotherapy to avoid the adverse cytocidal or cytostatic effects of immunotherapy. There were no significant differences in the proportion of patients with combination therapy involving chemotherapy between the antecedent and non-antecedent surgery groups (Table 1B).

Among a group of Japanese healthy adults $(n=32)$ serving as control subjects, the absolute number (mean \pm $\mathrm{SD})$ of $\mathrm{CD} 3+\alpha \beta \mathrm{TCR}+, \mathrm{CD} 4+$, and CD8+ T lymphocytes measured by cytometry was $1247 \pm 320,806 \pm 199$, and $508 \pm 181$ cells $/ \mu \mathrm{L}$, respectively, and the CD4/CD8 ratio was 0.8 (0.66 - 2.90). The proportions of CD4+ and CD8+ T cells were $64.6 \%$ and $40.7 \%$, respectively. The phenotypic proportions of CD4+ and CD8+ T cells in the total cohort of the 34 patients before the start of adoptive immunotherapy were similar to $(66.2 \%)$ and lower than $(28.6 \%)$ the values of the healthy controls, respectively (Table 2(A)).

Peripheral blood samples were obtained before the first, fourth, and sixth infusions of $\alpha \beta$ T cells. The num- 
ber of patients with $\alpha \beta$ T cell numbers $<0.3 \times 10^{7}$ in peripheral blood at the beginning of each infusion was compared between the two groups, and a statistically significant difference was observed at the first and sixth infusion time using Fisher's exact probability test and the Mantel-Haenszel procedure $(\mathrm{p}=0.0363)$ (Table 2(B)). This finding suggests that patients' immunological condition was superior in the antecedent surgery group following one course of immunotherapy, even though the same amount of augmented $\alpha \beta$ T cells $\left((3-10) \times 10^{9}\right)$ was infused each time in both groups.

The change in the CD4/CD8 ratio before and after one course of immunotherapy is shown in Table 3. Among the total cohort of 34 patients there was no significant difference in the CD4/CD8 ratio $(p=0.0766)$. However, the antecedent surgery group showed a significant decrease in the ratio $(p=0.0177)$, although the non-antecedent surgery group showed no significant change $(\mathrm{p}=$ 0.3050 ) despite a tendency for decrease after one course of immunotherapy (Table 3(A), Figure 1). Further analysis of the number of patients with a decrease or increase in CD4 and CD8 T cell numbers after one course of immunotherapy revealed that the antecedent surgery group had a significant increase in CD8 $\mathrm{T}$ cell number $(\mathrm{p}=$ 0.0002 ) but no change in CD4 $\mathrm{T}$ cell number compared with the non-antecedent surgery group ( $p=$ N. S.), whereas the non-antecedent surgery group showed a significant increase in CD8 T cells number $(p=0.0134)$ (Table 3(B)). These results (Table 3 ) reveal that the decreasing tendency of the $\mathrm{CD} 4 / \mathrm{CD} 8$ ratio in the antecedent surgery group depended mostly on an increase in CD8 T cells and not on CD4 T cell number. As CD8 T cells are cytotoxic and kill cancer cells, a significant in- crease in the number of CD8 $\mathrm{T}$ lymphocytes may act to improve the anticancer suppressive activity of the patient's immune system during immunotherapy.

Many physicians including Egawa, the founder of Japanese clinical immunotherapy who conducted the first clinical investigation of immunotherapy for cancer on

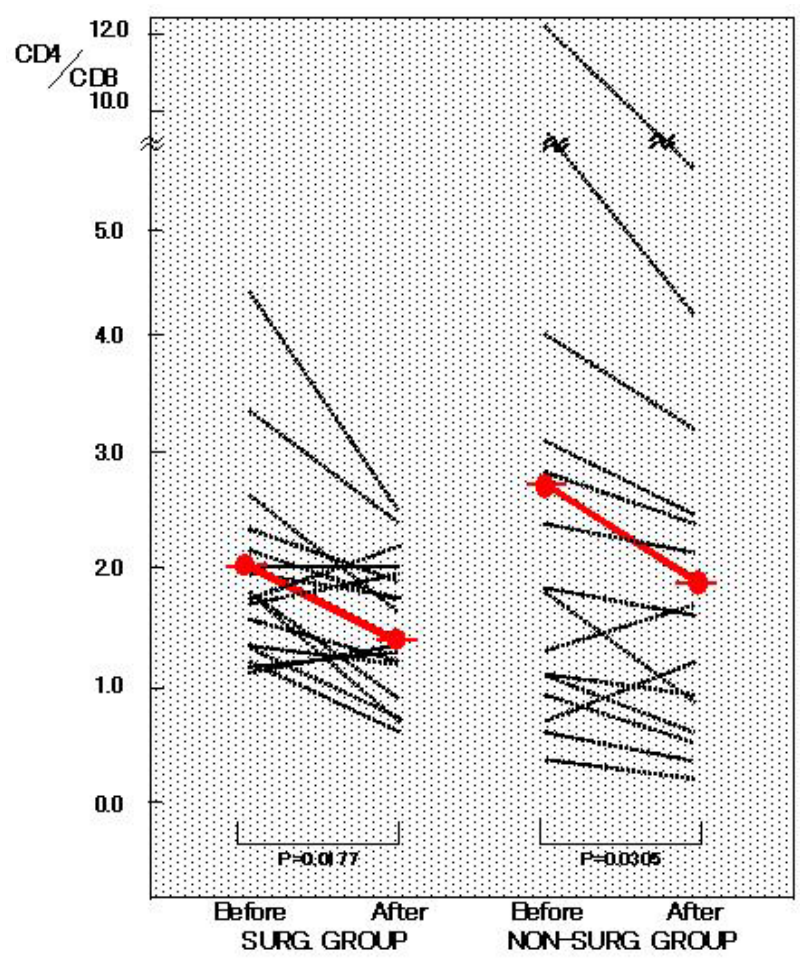

Figure 1. Change in the CD4/CD8 ratio before and after one course of immunotherapy.

Table 2. Phenotypes of healthy control and advanced cancer patients.

(A) Comparison of peripheral blood immunocyte phenotypes between health control and advanced cancer patients.

\begin{tabular}{cccc}
\hline phenotypes & healthy control $(\mathrm{N}=32)$ & patients before IT $(\mathrm{N}=34)(\%$ of control $)$ & patients after one course of IT (N=34) (\% of control) \\
\hline $\mathrm{CD} 3+\mathrm{T}$ & $1247 \pm 320$ cells $/ \mu \mathrm{L}$ & $927.5 \pm 387$ cells $/ \mu \mathrm{L}(74.4 \%)$ & $1032 \pm 356$ cells $/ \mu \mathrm{L}(82.8 \%)$ \\
$\mathrm{CD} 4+\mathrm{T}$ & $806 \pm 199$ & $614.5 \pm 252(76.2 \%)$ & $611.5 \pm 248(75.9 \%)$ \\
$\mathrm{CD} 8+\mathrm{T}$ & $508 \pm 181$ & $266 \pm 158(52.3 \%)$ & $358.9 \pm 204.7(70.6 \%)$ \\
$\mathrm{CD} 4 / \mathrm{CD} 8$ & $0.6(0.66 \sim 2.9)$ & $2.43 \pm 1.7(300 \%)$ & $1.80 \pm 1.1(225 \%)$ \\
\hline
\end{tabular}

(B) Number of patients with $\alpha \beta$ T cells number less than $0.3 \times 10^{7}$ at the beginning of each infusion time.

\begin{tabular}{|c|c|c|c|}
\hline IT infusion & $\begin{array}{l}\text { Antecedent surgery group } \\
\qquad(\mathrm{n}=19)\end{array}$ & Non-antecedent surgery group $(n=15)$ & $P$ value \\
\hline 1 st & $4(21.1 \%)$ & $7(46.7 \%)$ & 0.0068 \\
\hline 4 th & $3(15.8 \%)$ & $1(6.7 \%)$ & 0.5014 \\
\hline 6 th & $2(10.5 \%)$ & $7(46.7 \%)$ & 0.00005 \\
\hline \multicolumn{3}{|c|}{ Mantel-Haenszel procedure among 3 levels } & 0.0363 \\
\hline
\end{tabular}

IT, immunotherapy. 
1386 Is the CD4/CD8 Ratio an Effective Indicator for Clinical Estimation of Adoptive Immunotherapy for Cancer Treatment?

Table 3. Change in CD4/CD8 ratio.

\begin{tabular}{|c|c|c|c|c|c|c|}
\hline \multicolumn{7}{|c|}{ (A) Change in the $\mathrm{CD} 4 / \mathrm{CD} 8$ ratio before and after immunotherapy } \\
\hline & \multicolumn{2}{|c|}{ Total $(\mathrm{n}=34)$} & \multicolumn{2}{|c|}{ Antecedent surgery group $(\mathrm{n}=19)$} & \multicolumn{2}{|c|}{ Non-antecedent surgery group $(\mathrm{n}=15)$} \\
\hline & before & after & before & after & before & after \\
\hline mean & 2.4293 & 1.8029 & 2.1078 & 1.56 & 2.8364 & 2.091 \\
\hline SD & 1.7293 & 1.1112 & 0.8099 & 0.5605 & 2.4259 & 1.5183 \\
\hline$P$ value & \multicolumn{2}{|c|}{0.0766 (N. S.) } & \multicolumn{2}{|c|}{0.0177} & \multicolumn{2}{|c|}{0.3050 (N. S.) } \\
\hline
\end{tabular}

(B) Comparison between patients who decreased or increased their CD4/CD8 cell counts or the $\mathrm{CD} 4 / \mathrm{CD} 8$ ratio after one course of immunotherapy

\begin{tabular}{ccc}
\hline & Antecedent surgery group & Non-antecedent surgery group \\
\hline CD4 & 10 & 7 \\
decrease & 9 & 8 \\
increase & N. S. & N.S. \\
P value & & \\
CD8 & 3 & 4 \\
decrease & 16 & 11 \\
increase & 0.0002 & 0.0134 \\
P value & & \\
CD4/CD8 & 14 & 13 \\
decrease & 5 & 2 \\
increase & 0.0042 & 0.00007 \\
P value & & \\
\hline
\end{tabular}

his brother, have suggested that patients can maintain ordinary daily life activities during immunotherapy until close to the end of their life. To clarify this postulation, in the present study we analyzed PS during one course of adoptive activated immunotherapy [7,11,12]. Table 4(A) shows analysis of the number of patients in whom PS improved after one course of immunotherapy (Figure 2). Among all patients there was a significant improvement in PS $(p=0.0077)$. However, in separate analyses, the non-antecedent surgery group did not show any significant improvement, whereas PS improved in the antecedent surgery group; there was a significant difference between the two groups $(\mathrm{p}=0.0179)$.

Next, the changing pattern of the CD4/CD8 ratio was analyzed by subdividing all patients into two groups: the "downward" group in which the CD4/CD8 ratio decreased while CD4 $\mathrm{T}$ cells were almost unchanged and CD8 $\mathrm{T}$ cells increased after immunotherapy and the "upward" group in which there was an increased CD4/ CD8 ratio. PS in the upward group showed a significantly worse tendency $(p=0.025)$, whereas it was not significantly changed in the downward group $(p=0.2393)$ during immunotherapy (Table 4(B)). Therefore, the increase in the CD4/CD8 ratio after immunotherapy may imply worse outcome during immunotherapy.

Median survival time in the antecedent and non-antecedent surgery groups were 33.2 months and 8.9 months, respectively (Figure 3). Analysis of the actuarial survival rate of the two groups after one course of immunotherapy with subsequent immunotherapy alone or in combination with chemotherapy revealed that the antecedent surgery group had a significantly superior response, as determined by the log-rank test $(\mathrm{p}=0.0298)$, even though there was a discrepancy in gender distribution between the two groups. This finding confirmed the result of a previous study showing that surgery before immunotherapy confers an important benefit even for patients with advanced cancer [10].

\section{Discussion}

Several indices have been used to evaluate the effectiveness of immunotherapy for cancer treatment. Most of these, however, estimate the suppression of cancer effects by tumor markers, reflect the toxicity of interferon- $\gamma$ 
Is the CD4/CD8 Ratio an Effective Indicator for Clinical Estimation of Adoptive Immunotherapy for Cancer Treatment? 1387

Table 4. Performance status and changing pattern of the CD4/CD8 ratio.

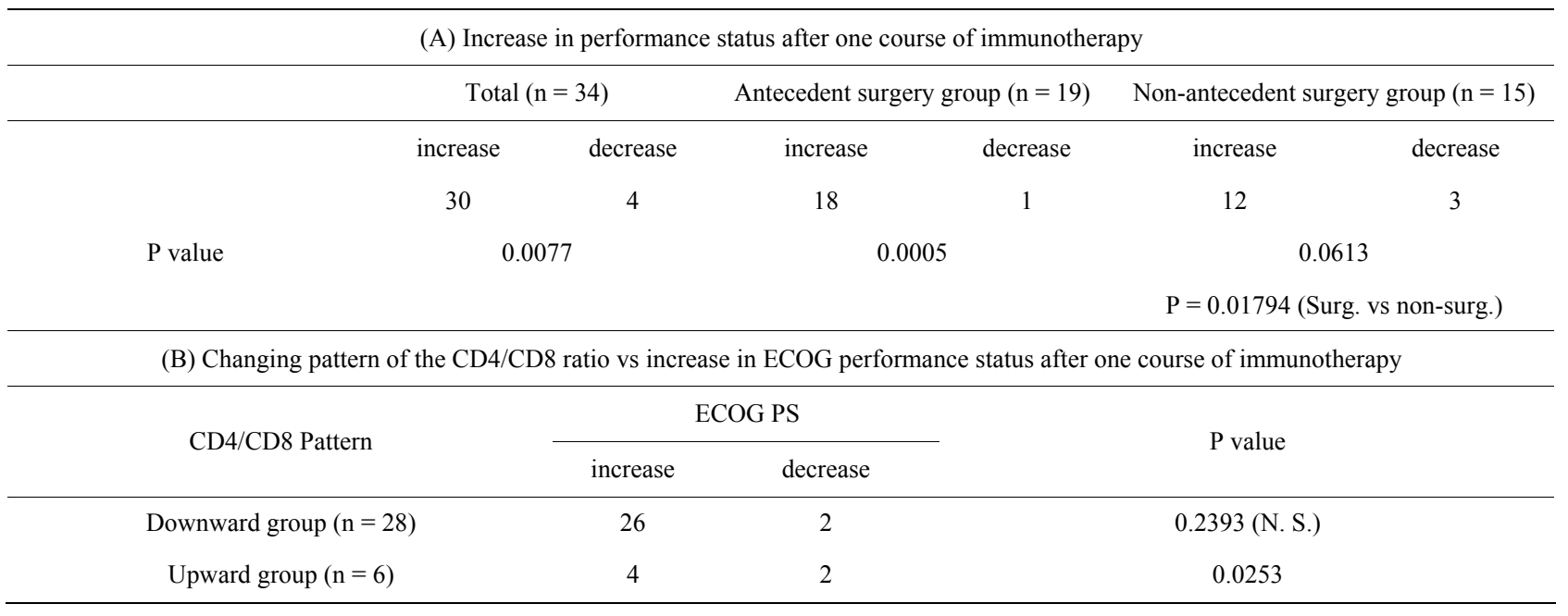

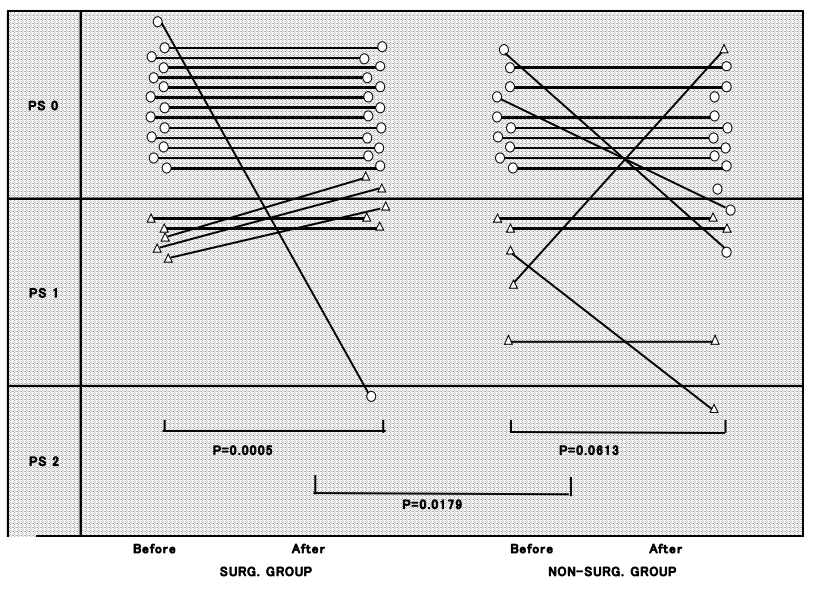

Figure 2. Change of ECOG performance status (P) before and after one course of immunotherapy.

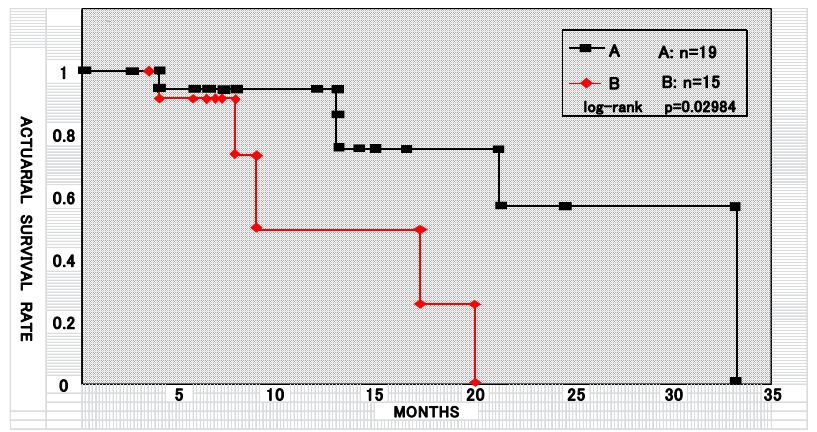

Figure 3. Actuarial survival curve of the antecedent surgical group (A) and the antecedent non-surgical group (B).

or tumor necrosis factor- $\alpha \mathrm{T}$ [15], or have an indirect influence on cancer invasiveness (e.g., the number of white blood cells, lymphocytes, or monocytes) [16,17] rather than provide a direct anticancer immunological index. Recent technological progress in flow cytometry has opened a new field of precise counting of immu- nological cells and revealed their detailed character in individual patients. Immunological cells in the blood, such as lymphocytes and monocytes, with fluorochromelabeled antibodies that bind specifically to lymphocyte surface antigens travel past a detector with an analogueto-digital conversion system under laser light. These scattered cells and fluorescence signals from cellular particles detected by the flow cytometer provide information about cell size, internal complexity, and relative fluorescence intensity. Lymphocyte subset percentages and absolute counts can be calculated using flow data from the beads and the sample. Flow cytometry can provide precise data on several types of immunological variables including CD3, CD4, CD8, and TCR pan $\alpha \beta$ T cells and the CD4/CD8 ratio.

In a previous study [12] involving 678 patients treated with autologous activated lymphocyte immunotherapy at our institute, we cultured their cells ex vivo under stimulation with immobilized anti-CD3 antibody and IL-2 and analyzed them by flow cytometry using monoclonal antibodies against CD3, CD4, CD8, CD56, and TCR $\gamma \delta$ [12]. The percentage (means $\pm \mathrm{SD}$ ) of $\mathrm{CD} 3+\mathrm{CD} 4+$ helper $\mathrm{T}$ cells and CD3+CD8 cytotoxic $\mathrm{T}$ cells in cultured cells were $31 \% \pm 15 \%$ and $61 \% \pm 15 \%$, respectively. Thus, $\alpha \beta$ $\mathrm{T}$ lymphocytes in these cultured lymphocytes contained more CD8+ lymphocytes compared with the total cohort of 34 patients in the present study. CD8 $+\mathrm{T}$ cells have a cytotoxic function in cancer cells and a suppressive ability against regulatory $\mathrm{T}$ lymphocytes $[8,11,17]$. Expanded CD8-rich $\mathrm{T}$ lymphocytes were infused intravenously once every 2 weeks up to 6 times during one course of adoptive immunotherapy. As a result, the CD4+ $\mathrm{T}$ cell numbers were maintained at almost the same level compared with levels before immunotherapy, whereas the CD8 T cell number increased significantly $(\mathrm{P}=0.05)$.

Takayama et al. [4] presented a clinical report of the 
feasibility and efficacy of adoptive immunotherapy to prevent recurrence of hepatocellular carcinoma in patients who underwent hepatectomy. From peripheral blood mononuclear cells cultured for 2 weeks with ex vivo IL-2 and immobilized anti-CD3 antibody, they obtained uncontaminated and viable activated $\mathrm{T}$ lymphocytes. The phenotype analysis of their activated T lymphocytes showed $87 \% \mathrm{CD} 3,25 \% \mathrm{CD} 8$, and $72 \% \mathrm{CD} 8 \mathrm{~T}$ cells. Autologous activated lymphocytes were infused five times during the first 6 months. Compared with no adjuvant treatment, adoptive immunotherapy significantly lowered the risk of recurrence after a median followup of 4.4 years.

There are several different kinds of immunotherapy using different phenotypic proportions of CD4 and CD8 $\mathrm{T}$ cells and differing CD4/CD8 ratios. For instance, Recchia et al. [18] presented the findings of maintenance immunotherapy in 100 patients with metastatic breast cancer who had received direct subcutaneous injection of low-dose IL-2 and administration of oral retinoic acid to prevent tumoricidal activity. Patients were followed for 3 years, and lymphocytes, NK cell numbers, and the CD4/ CD8 ratio were found to increase significantly $(p=0.05)$ each year compared with baseline. However, since there was an interval of 1 year between each measurement point, it is difficult to analyze the factors that may have contributed to increasing the $\mathrm{CD} 4 / \mathrm{CD} 8$ ratio.

The results of the analysis of the CD4/CD8 ratio in the present study clearly show that within 3 months from the start of one course of adoptive activated $\mathrm{T}$ lymphocyte immunotherapy, it was possible to estimate the effectiveness of immunotherapy even for patients with advanced cancers treated with not only immunotherapy alone but also combination therapy involving other conventional therapies such as chemotherapy or radiotherapy. Overall, $73.5 \%$ of our patients received combination therapy with chemotherapy.

In this study, a downward tendency of the CD4/CD8 ratio during one course of immunotherapy suggested an active immunological response against cancer invasion while an upward tendency suggested a worse immunological response during immunotherapy, indicating the possible timing of the next therapy for further improvement of the patient's immunological ability.

As previously reported [10], prior surgery improved the outcome of immunotherapy. Actuarial survival curves in the antecedent and non-antecedent surgery groups showed an additional long-term supportive effect of adoptive activated $\mathrm{T}$ lymphocyte immunotherapy in the former group $(p=0.0298)$. Patients then have the chance to choose more effective therapy 3 months after the first immunotherapy, and there are several options of immunotherapy treatment for patients proceeding to the next step. Options include $\gamma \delta$ T cell therapy [19], NK cell the- rapy [20], and dendritic cell vaccine therapy [21,22] with additional selection tests such as HLA typing. Immunohistochemical staining using pathological tissue specimens obtained in the operating theater in cases of antecedent surgery indicates NK cell therapy for MHC1negative patients. NK cell therapy is also provided for patients with a peripheral blood NK cell number that is diminished or patients who use antibody-dependent cellular cytotoxicity-containing drugs such as cetuximab or trastuzumab as combination immunotherapy $[23,24]$. NK cell therapy is also effective for patients who have not shown an effective response to $\alpha \beta \mathrm{T}, \gamma \delta \mathrm{T}$, cytotoxic $\mathrm{T}$ lymphocytes, and dendritic cell vaccine immunotherapy.

There is some evidence of an association between immunological ability and PS [7]. The present study showed a statistically significant association between change in the CD4/CD8 ratio before and after one course of adoptive immunotherapy and PS among different groups; the antecedent surgery group showed an important benefit of immunotherapy compared with the non-antecedent surgery group $(p=0.0179)$. Moreover, downward or upward change in the pattern of the CD4/CD8 ratio before and after one course of adoptive activated $\mathrm{T}$ lymphocyte immunotherapy revealed a long-term trend in PS. Indeed patients with good PS under immunotherapy maintained good QOL nearly to the end of their life. Change in the pattern of the $\mathrm{CD} 4 / \mathrm{CD} 8$ ratio suggests reasonable correlation with these phenomena based upon patient QOL.

Regulatory $\mathrm{T}\left(\mathrm{T}_{\mathrm{reg}}\right)$ lymphocyte number is not generally measured as a commercially available index but has been experimentally studied in the laboratory and in several clinical trials to date [25-28]. $\mathrm{T}_{\text {reg }}$ cells represent $5 \%$ - $10 \%$ of the peripheral CD4 T lymphocytes and are important supportive regulators of immune tolerance. In anticancer immunity, $T_{\text {reg }}$ cells may disturb beneficial tumor-specific responses. When $T_{\text {reg }}$ cell numbers increase to some extent, immune suppression appears to be inactivated [25]. Shirabe et al. [26] reported an important subpopulation balance between CD8 $+\mathrm{T}$ cells and $\mathrm{T}_{\text {reg }}$ cells in autologous tumor-infiltrating $\mathrm{T}$ lymphocyte immunotherapy for hepatocellular carcinoma using immunohistochemical analysis of paraffin-embedded tumor tissue.

Although the mechanisms involved in immune suppression are not fully understood in this condition, the decrease in the $\mathrm{CD} 4 / \mathrm{CD} 8$ ratio clearly appears before the increase in $T_{\text {reg }}$ cell count presenting with an active increase in CD8 T cells while CD4 T cells showed consistently stable cell numbers. An unchanged and stable CD4 $\mathrm{T}$ cell count may imply that the increase in $\mathrm{T}_{\text {reg }}$ cells appears at a later stage of immunological response compared with the decrease in the CD4/CD8 ratio during the initial 3 months of adoptive immunotherapy. The time 
delay between the CD4/CD8 ratio decrease and $\mathrm{T}_{\text {reg }}$ cell increase is beneficial for clinical use of the CD4/CD8 ratio as an index of immunological response, although the immunosuppressive action itself is explained more precisely by the $T_{\text {reg }}$ cell number.

\section{Conclusion}

In conclusion, in this preliminary clinical study, we have confirmed that the $\mathrm{CD} 4 / \mathrm{CD} 8$ ratio provides a valuable decision-making index for adoptive immunotherapy with or without other conventional therapies such as chemotherapy and/or radiotherapy at any stage of cancer including advanced disease, by measurement within 3 months of one course of immunotherapy. Patients may then proceed with more precise immunotherapy or other treatment according to the changing pattern of the CD4/ CD8 ratio. Further studies with a focus on different kinds of immunological response of cancer in different organs under several different kinds of immunotherapy are necessary to understand the underlying mechanisms and to develop new therapeutic strategies.

\section{Acknowledgements}

We thank Dr Atsumi Noguchi for providing technical assistance on flow cytometry.

\section{REFERENCES}

[1] S. A. Rosenberg, M. T. Lotse, L. M. Mull, S. Leitman, A. E. Chang, J. T. Votto, C. A. Seipp and C. Simpson, "A New Approach to the Therapy of Cancer Based on the Systemic Administration of Autologous LymphokineActivated Killer Cells and Recombinant Interleukine-2," Surgery, Vol. 100, No. 2, 1986, pp. 262-272.

[2] K. Egawa, "Immuno-Cell Therapy in Japan," Anticancer Research, Vol. 24, 2004, pp. 3321-3326.

[3] H. Kimura and Y. Yamaguchi, "A Phase III Randomized Study of Interleukin-2 Lymphokine-Activated Killer Cell Immunotherapy Combined with Chemotherapy or Radiotherapy after Curative or Non-Curative Resection of Primary Lung Carcinoma," Cancer, Vol. 80, No. 1, 1997, pp. 42-49.

[4] T. Takayama, T. Sekine, M. Makuuchi, S. Yamasaki, T. Kosuge, J. Yamamoto, K. Shimada, M. Sakamoto, S. Hirohashi, Y. Ohashi and T. Kakizoe, "Adoptive Immunotherapy to Lower Postsurgical Recurrence Rates of Hepatocellular Carcinoma: A Randomized Trial," Lancet, Vol. 356, No. 9232, 2000, pp. 802-807. http://dx.doi.org/10.1016/S0140-6736(00)02654-4

[5] S. Goto, T. Kaneko, Y. Miyamoto, M. Eriguchi, A. Kato, T. Akiyama, K. Fujimoto, H. Tomonaga and K. Egawa, "Combined Immuno-Cell Therapy Using Activated Lymphocytes and Monocytes-Derived Dendritic Cells for Malignant Melanoma," Anticancer Research, Vol. 25, 2005, pp. 3741-3746.

[6] T. Kaneko, S. Goto, A. Kato, A. M. Akeyama, K. To- monaga, Y. Fujimoto, Y. Miyamoto, M. Eriguchi and K. Egawa, "Efficacy of Immuno-Cell Therapy in Patients with Advanced Pancreatic Cancer," Anticancer Research, Vol. 25, 2005, pp. 3709-3714.

[7] K. Iwai, K. Soejima, S. Kudoh, Y. Umezato, T. Kanako, K. Yoshimori, H. Tokuda, T. Yamaguchi, A. Mizoo, Y. Setoguchi, T. Kamigaki, Y. Fujimoto and S. Goto, "Extended Survival Observed in Adoptive Activated T Lymphocyte Immunotherapy for Advanced Lung Cancer: Results of a Multicenter Historical Cohort Study," Cancer ImmunolImmunother, Vol. 61, No. 10, 2012, pp. 17811790.

[8] G. Parmiani and A. Anichini, "T Cell Infiltration and Prognosis in HCC Patients," Journal of Hepatology, Vol. 45, No. 2, 2006, pp. 178-181. http://dx.doi.org/10.1016/j.jhep.2006.06.005

[9] A. F. Carpentier and Y. Meng, "Recent Advances in Immunotherapy for Human Glioma," Current Opinion in Oncology, Vol. 18, No. 6, 2006, pp. 631-636.

[10] G. Shindo, T. Endo, M. Onda, Y. Miyamoto, T. Kaneko and S. Goto, "Immuno-Cell Therapy with Antecedent Surgery Has Superior Actuarial Survival to Immuno-Cell Therapy without Antecedent Surgery for Advanced Cancers," Cancer Immunology, Immunotherapy, Vol. 60, No. 10, 2011, pp. 1397-1403. http://dx.doi.org/10.1007/s00262-011-1044-0

[11] K. Egawa, "On the Safety Assurance of All Processing Carried Out on Medical Institutions for Autologous Immune-Cell Therapy," Human Cell, Vol. 17, No. 1, pp. 1-6. http://dx.doi.org/10.1111/j.1749-0774.2004.tb00014.x

[12] S. Goto, A. Noguchi, H. Jinguji and M. Takahara, "The Therapeutic Potential of Immuno-Cell Therapy of Cancer in Combination with Aminobiophosphonates" Anticancer Research, Vol. 26, pp. 3989-3995.

[13] M. J. Fulwyler, "Electronic Separation of Biological Cells by Volume," Science, Vol. 150, No. 12, 1965, pp. 910911.

[14] L. A. Herzenberg, M. H. Julius and T. Masada, "Demonstration That Antigen-Binding Cells Are Precursors of Antibody-Producing Cells after Purification with Fluorescence Activated Cell Sorter," PNAS, Vol. 69, No. 7, 1972, pp. 1934-1938.

http://dx.doi.org/10.1073/pnas.69.7.1934

[15] A. Agarwal, S. Verma, U. Burra, N. S. Murthy, N. K. Mohanty and S. Saxena, "Flow Cytometric Analysis of Th1 and Th2 Cytokines in PBMCs as a Parameter of Immunological Dysfunction of Superficial Transitional Cell Carcinoma of Bladder," Cancer Immunology, Immunotherapy, Vol. 55, No. 6, 2006, pp. 734-743. http://dx.doi.org/10.1007/s00262-005-0045-2

[16] Y. Wada, O. Nakashima, R. Kutami, O. Yamamoto and M. Kojiro, "Clinicopathological Study on Hepatocellular Carcinoma with Lymphocytic Infiltration," Hepatology, Vol. 27, No. 2, 1998, pp. 404-414. http://dx.doi.org/10.1002/hep.510270214

[17] D. J. Powell Jr., M. E. Dudley, K. A. Hogan, J. R. Wunderlich and S. A. Rosenberg, "Adopted Transfer of Vaccine-Induced Peripheral Blood Mononuclear Cells to Patients with Metastatic Melanomas Following Lymphode- 
1390 Is the CD4/CD8 Ratio an Effective Indicator for Clinical Estimation of Adoptive Immunotherapy for Cancer Treatment?

pletion," The Journal of Immunology, Vol. 177, No. 9, 2006, pp. 6527-6539.

[18] F. Recchia, G. Sica, G. Candeloro, S. Necozione, R. Bisegna, M. Bratta and S. Rea, "Maintenance Immunotherapy in Metastatic Breast Cancer," Oncology Reports, Vol. 20, 2008, pp. 1173-1179.

[19] M. Sakamoto, J. Nakajima, T. Murakawa, T. Fukami, Y. Yoshida, T. Murayama, S. Takamoto, H. Matsushita and K. Kakimi, "Adoptive Immunotherapy for Advanced Non-Small Lung Cancer Using Zoledronate-Expanded $\gamma \delta$ T Cells: A Phase 1 Clinical Study," The Journal of Immunology, Vol. 34, No. 2, 2011, pp. 202-211.

[20] E. Ishikawa, K. Tsuboi, K. Saijo, H. Harada, S. Takano, T. Nose and T. Ohno, "Autologous Natural Killer Cell Therapy for Human Recurrent Malignant Glioma," Anticancer Research, Vol. 24, 2004, pp. 1861-1872.

[21] A. Kuemmel, K. Single, F. Bittinger, A. Faldum, L. H. Schmidt, M. Sebastia, P. Micke, C. Taube, R. Buhl and R. Wiewrodt, "TA-MUC1 Epitope in Non-Small Cell Lung Cancer," Lung Cancer, Vol. 63, No. 1, 2009, pp. 98-105. http://dx.doi.org/10.1016/j.lungcan.2008.04.005

[22] V. Mazzaforro, J. Coppa, M. G. Garrabba, L. Rivoltini, M. Schiavo, E. Regalia, L. Mariani, T. Camerini, A. Marchiano, S. Andreola, R. Camerini, M. Corsi, J. J. Lewis, P. K. Srivastava and G. Parmiani, "Vaccination with Autologous Tumor-Derived Heat-Shock Protein Gp 96 after Liver Resection for Metastatic Colorectal Cancer," Clinical Cancer Research, Vol. 9, No. 9, 2003, pp. 3235-3245.

[23] H. Norell, I. Poschke, J. Charo, W. Z. Wei, L. Erskine, M. P. Piechocki, K. L. Knutson, J. Bergh, E. Lidbrink and R. Kiessling, "Vaccination with a Plasmid DNA Encoding HER-2/neu Together with Low Dose of GM-CSF and
IL-2 in Patients with Metastatic Breast Carcinoma: A Pilot Clinical Trial," Journal of Translational Medicine, Vol. 8, No. 6, 2010, pp. 53-64. http://dx.doi.org/10.1186/1479-5876-8-53

[24] L. A. Emens, "Re-Purposing Cancer Therapeutics for Breast Cancer Immunology," Cancer Immunology, Immunotherapy, Vol. 61, No. 8, 2012, pp. 1299-1305. http://dx.doi.org/10.1007/s00262-012-1247-z

[25] H. Nishikawa and S. Sakaguchi, "Regulatory T Cells in Tumor Immunity," International Journal of Cancer, Vol. 127, No. 4, 2010, pp. 759-767.

[26] K. Shirabe, T. Motomura, J. Muto, T. Toshima, R. Matono, Y. Mano, K. Takeishi, H. Ijichi, N. Harada, H. Uchiyama, T. Yoshizumi, A. Takatomi and Y. Maehara, "Tumor Infiltrating Lymphocytes and Hepatocellular Carcinoma: Pathology and Clinical Management," International Journal of Clinical Oncology, Vol. 15, No. 6, 2010, pp. 552-558.

http://dx.doi.org/10.1007/s10147-010-0131-0

[27] B. Fong, R. Jin, X. Wang, M. Safaee, D. N. Lisiero, I. Yang, G. Li, L. M. Liau and R. M. Prins, "Monitoring of Regulatory T Cell Frequencies and Expression of CTLA4 on T Cells, Before and after DC Vaccination, Can Predict Survival in GBM Patients," PLoS ONE, Vol. 7, No. 4, 2012, pp. 1-9.

[28] P. Salama, C. Stewart, C. Forrest, C. Platell and B. Iacopetta, "FoxP3 ${ }^{+}$Cell Density in Lymphoid Follicles from Histlogically Normal Mucosa Is a Strong Prognostic Factor in Early Stage Colon Cancer," Cancer Immunology, Immunotherapy, Vol. 61, No. 8, 2012, pp. 11831190. http://dx.doi.org/10.1007/s00262-011-1191-3 